\title{
UTILIZAÇÃO DO ADESIVO METIL-2-CIANOACRILATO E FIO DE NÁILON NA REPARAÇÃO DE FERIDAS CUTÂNEAS DE CÃES E GATOS
}

\author{
UTILIZATION OF THE METHYL-2-CYANOACRYLATE ADHESIVE AND THE NYLON \\ SUTURE IN SURGICAL SKIN WOUNDS OF DOGS AND CATS
}

\author{
Vanja Andrade Gueiros ${ }^{1}$ Andréa Pacheco Batista Borges ${ }^{2}$ João Carlos Pereira da Silva ${ }^{3}$ \\ Tatiana Schimitz Duarte ${ }^{4}$ Kátia Linhares Franco $^{4}$
}

\section{RESUMO}

\begin{abstract}
Com o objetivo de avaliar e comparar clínica $e$ histologicamente o uso do adesivo metil-2-cianoacrilato e do fio de náilon na reparação de feridas cirúrgicas de pele, foram utilizados cinco cães e cinco gatos adultos, clinicamente sadios. Seguindo o protocolo anestésico e cirúrgico habitual para cada espécie, foram feitas cinco incisões na pele da região costal do lado esquerdo e cinco do lado direito, com aproximadamente dois centímetros de comprimento. As feridas cirúrgicas do lado direito foram suturadas com fio de náilon cirúrgico 3-0 e as do lado esquerdo foram aproximadas e fixadas com o metil-2cianoacrilato em ambas as espécies. Os animais foram submetidos a avaliações clínicas a cada três dias. Foram retirados fragmentos de pele para realização de biopsias aos três, seis, nove, doze e quinze dias após a cirurgia. Os resultados obtidos, tanto em cães quanto em gatos, não revelaram diferença clínica ou histológica entre os tratamentos utilizados.
\end{abstract}

Palavras-chave: metil-2-cianoacrilato, sutura de pele, fio de náilon.

\section{SUMMARY}

The purpose of this study is to evaluate and compare clinically and histologically the use of methyl-2-cyanoacrylate adhesive versus the nylon's suture in skin wounds closure. There were five adult mongrel dogs and cats, clinically healthy used. Following anaesthetical routine and surgical protocol, five incisions were made in the left costal region, and other five in right costal region, about $2 \mathrm{~cm}$ in length, in both especies. The right side costal wounds were sutured with surgical nylon 3-0, and in the left side costal wounds methyl-2-cyanoacrylate was applied, in both species. The animals were submitted to clinical evaluation every three days, and a biopsy was realized at three, six, nine, twelve and fifteen days after the surgery. In both species, the results did not show any clinical or histologic difference when comparing the used treatments.

Key words: metyl-2-cyanoacrylate, skin suture, nylon's suture.

\section{INTRODUÇÃO}

Nas últimas três décadas, um grande número de pesquisas foram realizadas utilizando adesivos tissulares derivados do ácido cianoacrílico em diversos tecidos e órgãos (JAVELET $\boldsymbol{e}$ al ., 1985; MIZRAHI et al., 1988; BORGES et al., 1993; GIRAY et al., 1995; QUINN et al., 1997; QURESHI et al., 1997; PELAGE et al., 1998; MAGALHÃES, 1999). Como vantagens da utilização do adesivo, podem-se citar a fácil aplicação, a diminuição do tempo de cirurgia, conseqüentemente, do tempo de anestesia geral (GOMEZ \& MORENO, 1993; MATTHEWS, 1993; BLANCO, 1994). Além disso, para redução de feridas traumáticas não há necessidade de material cirúrgico para a sua aplicação, nem anestesia local (MIZRAHI $\boldsymbol{e t}$ al., 1988; BLANCO, 1994).

\footnotetext{
${ }^{1}$ Médico Veterinário, Especialista em Clínica e Cirurgia de Pequenos Animais, Departamento de Veterinária, Universidade Federal de Viçosa (UFV).

${ }^{2}$ Médico Veterinário, Professor Adjunto do Departamento de Veterinária, Doutor, (UFV), Campus Universitário, Av. P.H.Rolfs s/n. 36571-000, Viçosa, MG. E-mail: andrea@mail.ufv.br. Autor para correspondência.

${ }^{3}$ Médico Veterinário, Professor Titular, Departamento de Veterinária, Doutor, UFV.

${ }^{4}$ Estudante de Medicina Veterinária, Iniciação Científica, UFV. 
As características físicas, químicas e biológicas dos cianoacrilatos variam de acordo com o tamanho da cadeia carbônica do radical alquil (PAPATHEOFANIS, 1989; TSENG et al., 1990; DEBONO, 1997). Sua toxicidade deve-se, provavelmente, aos produtos resultantes da sua degradação, como o formaldeído (TSENG et al., 1990), ou à liberação de hidroperóxidos que ativam a biossíntese de prostaglandina e tromboxanos que participam na oxidação e lise da membrana celular (PAPATHEOFANIS, 1989).

Logo após a sua aplicação, esses adesivos sofrem reação de hidroxilação que resulta no endurecimento do produto (GIRAY et al., 1995; DEBONO, 1997). A polimerização acontece através de reação exotérmica e ação aglutinante (QUINN $\boldsymbol{e t}$ $\boldsymbol{a l} .$, 1997) e varia de meio a cinco minutos, dependendo da presença e da quantidade de fluidos corporais (GOMEZ \& MORENO, 1993). O adesivo é gradualmente biodegradado na presença de água e removido do sítio de implantação. Quanto mais lenta a degradação, menor será o efeito tóxico, pois a lenta liberação dos produtos permite um metabolismo mais efetivo dos mesmos, provocando reação inflamatória de menor intensidade (DEBONO, 1997).

A força de adesão depende da morfologia do tecido e da preparação das superfícies a serem reaproximadas e aderidas (QURESHI $\boldsymbol{e t}$ al., 1997). Em estudo realizado por KILPIKARI et al. (1986), foi observado que a força de adesão inicial entre as duas superfícies é alta, mas diminui após 3 semanas e tende a quebrar-se ou soltar-se em meio aquoso após 3 a 6 semanas.

Estudos revelaram que feridas contaminadas por bactérias e fechadas com cianoacrilato tiveram contagem de bactérias gram positivas significativamente menor do que feridas suturadas com fio de náilon cirúrgico (HOWELL et al., 1995). Sabe-se que esse efeito antibacteriano aumenta com a diminuição da cadeia do grupo alquil e que essa ação parece estar relacionada com a polimerização do adesivo, mas que, possivelmente, não possui duração muito longa (MATTHEWS, 1993).

O náilon é um polímero de cadeia longa que se encontra disponível nas formas monofilamentar e multifilamentar (HULSE \& JOHNSON, 1997). É difícil de ser amarrado, sendo necessários semi-nós adicionais para se obter segurança, produzindo, portanto, um nó volumoso. Apesar de induzir uma resposta inflamatória mínima, ele se mantém como um corpo estranho dentro do tecido, o que prolonga as fases inflamatória e de debridamento do processo de cicatrização (BOOTHE, 1998). A reação flogística presente nessas situações é caracterizada por modificações humorais e celulares, inician- do com a coagulação do sangue e seguindo com uma série concatenada de eventos, destacando-se os fenômenos vasculares e exsudativos, a proliferação fibroblástica, a neoformação vascular, a proliferação e migração de células epiteliais e a contração da ferida (ROBBINS $\boldsymbol{e t}$ al., 1991 e MAGALHÃES, 1999).

O objetivo deste trabalho foi avaliar e comparar clínica e histologicamente o uso do adesivo tissular metil-2-cianoacrilato e do fio de náilon na reparação de feridas cirúrgicas cutâneas de cães e gatos.

\section{MATERIAL E MÉTODOS}

Foram utilizados cinco cães e cinco gatos adultos, machos e fêmeas, sem raça definida, clinicamente sadios, provenientes, respectivamente, do canil experimental e do Biotério do Departamento de Veterinária da Universidade Federal de Viçosa. Os cães pesavam em média $10 \mathrm{~kg}$ e os gatos, $3 \mathrm{~kg}$. Os animais foram mantidos em baias individuais, alimentados uma vez ao dia com ração comercial e água ad libidum.

Após jejum hídrico e alimentar, os cães foram sedados com acepromazina ${ }^{\mathrm{a}}$ na dose de $0,1 \mathrm{mg} / \mathrm{Kg}$ de peso vivo, por via intravenosa. As regiões costais de ambos os lados foram preparadas para a cirurgia, mediante tricotomia, desengorduramento com éter e anti-sepsia com álcool iodado, e, em seguida, os animais foram anestesiados com Tiopental sódico ${ }^{\mathrm{b}}$ na dose de $12,5 \mathrm{mg} / \mathrm{kg}$ de peso vivo, por via intravenosa.

Os gatos foram pré-tratados com sulfato de atropina ${ }^{c}$ na dose de $0,04 \mathrm{mg} / \mathrm{kg}$ de peso vivo, por via subcutânea e, posteriormente, anestesiados com a associação de cetamina ${ }^{\mathrm{d}}$ na dose de $10 \mathrm{mg} / \mathrm{kg}$ e xilazina $^{\mathrm{e}}$ na dose de $1,0 \mathrm{mg} / \mathrm{kg}$ de peso vivo, por via intramuscular. As feridas cirúrgicas foram realizadas de maneira similar aos cães.

Em ambas as espécies, nas referidas regiões costais, foram feitas cinco incisões de pele, com auxílio de um bisturi, no sentido dorso-ventral, medindo cerca de $2 \mathrm{~cm}$ de extensão. De acordo com sua localização, as incisões foram denominadas craniodorsal, mediodorsal, caudodorsal, cranioventral e caudoventral. Após realização de hemostasia por compressão, as incisões do lado direito foram suturadas com fio de náilon ${ }^{\mathrm{f}} 3-0$, por meio de três pontos no padrão simples separado. As incisões do lado esquerdo foram fixadas com o metil-2-cianoacrilato ${ }^{g}$ sobre a pele, aplicado em gotas em espaços de aproximadamente $5 \mathrm{~mm}$, respeitando a justaposição anatômica das bordas das feridas. A polimerização do adesivo foi observada através do toque digital. 
No pós-operatório, tanto os cães quanto os gatos usaram roupas de proteção ("vestidos") para prevenir a interferência nas feridas cirúrgicas. Em nenhum momento do experimento, foi administrado aos animais antibióticos e antiinflamatórios.

O exame clínico foi realizado a cada três dias e constou de observação das feridas, verificando a eventual presença de reação inflamatória, deiscência de sutura, afastamento das bordas da ferida, fragmentação e eliminação do adesivo metil-2cianoacrilato. Para exame histológico, foram obtidas amostras em forma de elipse, contendo toda a extensão da ferida, em ambos os lados, aos três, seis, nove, doze e quinze dias nas feridas craniodorsais, mediodorsais, caudodorsais, cranioventrais e caudoventrais, respectivamente.

De cada amostra, foram retirados dois fragmentos, sendo um perpendicular e o outro paralelo à linha de sutura, os quais foram fixados em formol tamponado a $10 \%$, processados segundo técnicas rotineiras e corados pela hematoxilinaeosina. Foram, então, avaliadas ao microscópio óptico quanto à reação tecidual, através de uma análise qualitativa descritiva, que se baseou naqueles elementos representativos do processo inflamatório e do processo reparativo, evidenciado principalmente pela presença de congestão, hemorragia, edema, necrose, exsudato neutrofílico, infiltrado mononuclear e tecido de granulação.

\section{RESULTADOS E DISCUSSÃO}

A hemostasia por compressão, utilizada neste experimento, foi eficiente, em ambas as espécies, mesmo sendo a hemorragia maior em cães que em gatos. A polimerização do metil-2-cianoacrilato, observada ao toque digital, ocorreu em torno de 30 segundos, após a aplicação do mesmo, semelhante ao relatado por BORGES et al. (1993) e GOMEZ \& MORENO (1993).

No presente experimento, optou-se pela proteção da ferida através do uso de "vestido" para que o animal não interferisse na ferida cirúrgica. JAVELET et al. (1985) relataram remoção do adesivo pelos animais que interferiram na ferida. Mesmo assim, em três cães e em um gato, houve interferência, com deiscência de ponto, e em um cão, ocorreu a presença de infecção. Por isso, a proteção da ferida é recomendada.

A aplicação dos adesivos é também indicada em regiões de tensão (MIZRAHI $\boldsymbol{e t} \boldsymbol{a l}$., 1988), mas a ferida não deve ser tensionada até os seis dias do pós operatório. Neste experimento, os animais podem ter provocado tensão na ferida por interferên- cia na mesma, provavelmente devido à reação inflamatória local causadora de prurido e dor.

Não existe a necessidade de procedimento pós-operatório para a retirada do adesivo, uma vez que o mesmo se tornou quebradiço a partir do nono dia, desprendendo-se facilmente. $\mathrm{O}$ afastamento das bordas das feridas também não ocorreu, tornando-se desnecessário o retorno do animal tratado com o adesivo, vantagem essa também observada por JAVELET et al. (1985), KILPIKARI $\boldsymbol{e t}$ al. (1986) e QUINN et al. (1997). Como vantagem adicional, a utilização do adesivo impede a presença de corpo estranho atuando como sítio para infecção, como nos casos de fios de sutura (MATTHEWS, 1993; HOWELL et al., 1995; QUINN et al., 1997; QURESHI et al., 1997; PELAGE et al., 1998).

O náilon foi o fio de escolha, por promover uma resposta tecidual mínima (HULSE \& JOHNSON, 1997), resultado observado também no presente estudo. A necessidade de fazer vários seminós, quando se utiliza o náilon, como recomendado por BOOTHE, (1998), fez com que, aparentemente, o tempo de aplicação do adesivo fosse menor do que o gasto para a confecção da sutura.

$\mathrm{O}$ exame histológico revelou que em gatos as reações teciduais foram, em linhas gerais, de menor intensidade do que nos caninos. É lícito supor que tal fato deva ser atribuído às diferenças entre as espécies. Os resultados obtidos aos três dias, em ambas as espécies e tratamentos, traduziam-se por predomínio de fenômenos vasculares e exsudativos (Figura 1a), correspondendo ao início de uma resposta inflamatória, como citado por ROBBINS et al. (1991) e QUINN et al. (1997).

Aos seis dias de pós-operatório, em ambas as espécies e tratamentos, os achados caracterizaram-se por diminuição da resposta inflamatória e início dos fenômenos reparativos de cura, representados pela fibroplasia (Figura 1b) e angiogênese, também descrito por ROBBINS et al. (1991) e MAGALHÃES (1999). Em linhas gerais, constatouse ainda que a exsudação neutrofílica foi mais acentuada nas feridas tratadas com fio de náilon do que naquelas com o adesivo.

A partir do nono dia, as alterações vasculares foram praticamente inexistentes em todos os animais e em ambos os tratamentos. Os fenômenos exsudativos, a exemplo dos seis dias, persistiram numa intensidade moderada em grande número de animais e em ambos os tratamentos. Da mesma forma, os fenômenos produtivos, caracterizados principalmente pela presença de tecido de granulação (Figura 1b), também se faziam presentes na maioria dos animais. As feridas que revelaram, após os seis dias de pós-operatório, intensificação dos 


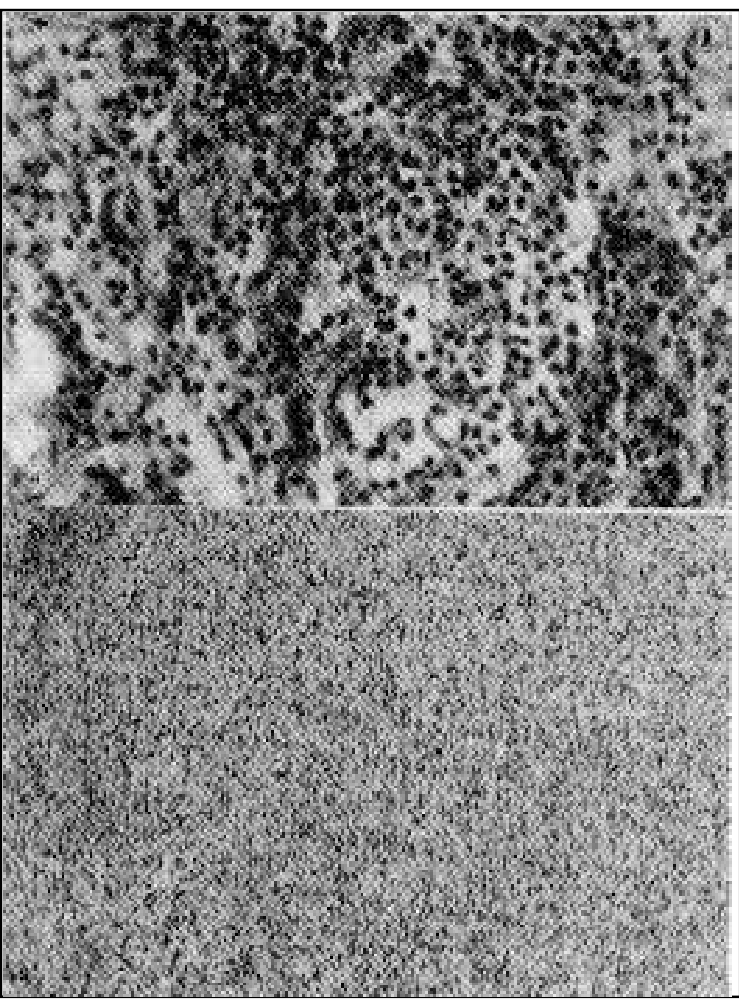

Figura 1 - A: Infiltrado de polimorfonucleares na região da ferida cirúrgica aproximada com metil-2-cianoacrilato, com 3 dias de pós-operatório, HE, 400x. B: Tecido de granulação na região da ferida cirúrgica aproximada com metil-2 cianoacrilato, com 6 dias de pós-operatório, $\mathrm{HE}, 400 \mathrm{x}$.

fenômenos vasculares e exsudativos, foram aquelas provavelmente contaminadas por microorganismos após o procedimento cirúrgico, e coincidiram, exatamente, com aquelas as quais os animais interferiram na ferida. A partir dos doze dias, observou-se nítida tendência de diminuição do exsudato neutrofílico em ambos os tratamentos; fato esse também notado com o tecido de granulação que revelou gradativa diminuição de sua celularidade e maior produção de fibras colágenas. Nessa fase, notou-se, ainda, uma completa reepitelização da ferida cirúrgica (Figura 2) em ambos os tratamentos. Aos quinze dias, observou-se a reparação efetiva de todas as feridas, em ambos tratamentos e em ambas as espécies, sendo, nos gatos, a resposta inflamatória de menor intensidade em ambos os tratamentos. A cicatriz do lado em que foi utilizado o adesivo apresentou-se mais linear e mais fina, sem vestígios de trauma feito pela agulha no momento da sutura. Esse fato foi também observado por BLANCO (1994) e GIRAY et al. (1995).

O metil-2-cianoacrilato é considerado um dos cianoacrilatos mais tóxicos, devido ao tamanho reduzido do radical alquil (PAPATHEOFANIS, 1989; TSENG et al., 1990; DEBONO, 1997). Toda-

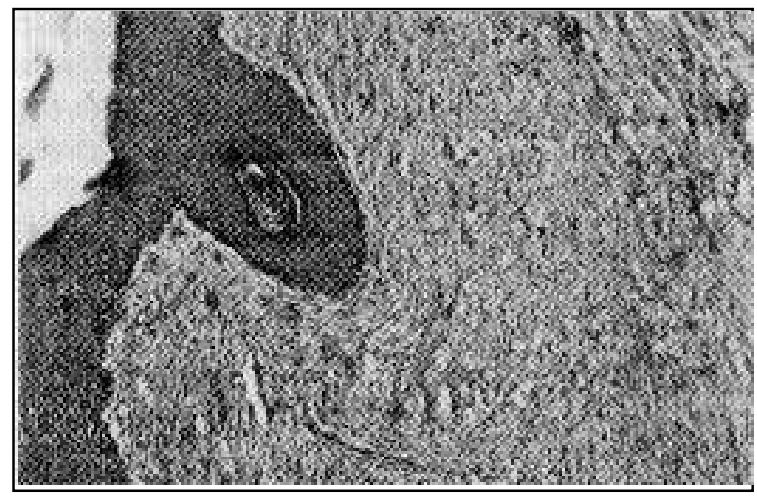

Figura 2 - Área de reepitelização completa (a), derme com produção de colágeno (b) e discreto infiltrado de polimorfonucleares (c) na ferida cirúrgica aproximada com metil-2-cianoacrilato, com 15 dias de pós-operatório, HE, $100 x$

via, acredita-se que devido a sua aplicação externamente à ferida de pele, e em pequena quantidade (gotas espaçadas), esses efeitos não tenham sido observados.

Com base nos resultados clínicos e histológicos obtidos e nas condições do experimento realizado, pode-se concluir que não há diferença entre o processo reparativo de ferida cirúrgica de pele tratada com sutura com náilon cirúrgico e com adesivo metil-2-cianoacrilato em cães e gatos. Além disso, observou-se que o adesivo metil-2cianoacrilato pode ser utilizado para o fechamento de pequenas feridas cirúrgicas de pele em cães e gatos.

\section{FONTES DE AQUISIÇÃO}

a - Acepromazina - Acepran - Univet

b - Tiopental sódico - Tiopental - Cristália.

c - Sulfato de Atropina - Atropina - Hipofarma - Brasil

d - Francotar - Virbac

e - Cloridrato de Xilazina - Rompum - Bayer

f - Ethilon (monofilament) - Ethicon

$\mathrm{g}$ - Super Bonder - Loctite

\section{REFERÊNCIAS BIBLIOGRÁFICAS}

BLANCO, L.P. Lip suture with isobutyl cyanoacrylate. Endodontics \& Dental Traumatology, v.10, n.1, p.15-18, 1994.

BOOTHE, H.W. Materiais de sutura, adesivos teciduais, grampeadores e grampos. In: SLATTER, D. Manual de cirurgia de pequenos animais. Rio de Janeiro : Guanabara Koogan, 1998. p.204-211.

BORGES, A.P.B., POMPERMAYEER, L.G., REZENDE, C.M.F., et al. Aspectos histológicos da consolidação de fraturas de fêmur em cães com esquírola fixada pelo adesivo butil-2-cianoacrilato. Arquivo Brasileiro de Medicina Veterinária e Zootecnia, v.45, n.4, p.375-383,1993. 
DEBONO, R. A simple, inexpensive method for precise application of cyanoacrylate tissue adhesive. Plastic \& Reconstructive Surgery, v.100, n.2, p.447-450, 1997.

GIRAY, C.B., SUNGUR, A., ATASEVER, A., $\boldsymbol{e} \boldsymbol{t} \boldsymbol{a l}$ Comparison of silk sutures and n-butil-2-cyanocrylatee on the healing of skin wounds. A pilot study. Australian Dental Journal, v.40, n.1, p.43-45, 1995.

GOMEZ, J. M., MORENO, J. Anastomosis of uterine serosa with cyanoacrylate versus sutures in rats. Acta Obstetric Gynecology Scandinavia, v.72, n.3, p.210-213, 1993.

HOWELL, J.M., BRESNAHAN, K.A, STAIR, T.O., et al. A. Comparison of effects of suture and cyanoacrylate tissue adhesive on bacterial counts in contamined lacerations. Antimicrobial Agents and Chemotherapy, v.39, n.2, p.559$560,1995$.

HULSE, D.A., JOHNSON, A.L. Biomaterials, suturing, and hemostasis. In: FOSSUM, T.W., HEEDLUND, C.S. HULSE, D.A., et al. Small animal surgery. Missouri : Mosby, 1997. p.42-47.

JAVELET, J., TORABINEJAD, M., DANFORTH, R. Isobutil cyanoacrylate: A clinical and histologic comparison with suters in closing mucosal incisions in monkeys. Oral Surgery, v.59, n.1, p.91-94, 1985.

KILPIKARI, J., LAPINSUO, M., TORMALA, P., et al. Bonding strength of alkyl-2-cyanoacrylates to bone in vitro. Journal of Biomedical Materials Research, v.20, n.1, p.1095-1102, 1986.

MAGALHÃES, A.C. Estudo comparativo entre o adesivo metil-2 cianoacrilato e o fio de náilon na reparação de feridas cirúrgicas provocadas experimentalmente na pele de eqüinos. Viçosa - MG, 1999. 28p. Monografia (Especialização em Clínica e Cirurgia de Grandes Animais) -
Curso de Especialização em Clínica e Cirurgia de Grandes Animais, Universidade Federal de Viçosa, 1999.

MATTHEWS, S. Tissue bonding: The bacteriological properties of a comercially - available cyanoacrylate adhesive. British Journal of Biomedical Science, v.50, n.1, p.17-20, 1993.

MIZRAHI, S., BICKEL. A., BEM-LAYISH, E. Use of adhesives in the repair of lacerations in children. Journal of Pediatric Surgery, v.23, n.4, p.312-313, 1988.

PAPATHEOFANIS, F.J. Cytotoxicity of alkyl-2-cyanoacrylate adhesives. Journal of Biomedical Materials Research, v.23, n.6, p.661-668, 1989.

PELAGE, J.P., HERBRETEAU, D., PAILlON, J.F., $\boldsymbol{e} \boldsymbol{t}$ al. Selective salpinography and Fallopian tubal occlusion with nbutyl-2-cyanoacrylate: Report of two cases. Radiology, v.207, n.3, p.809-812, 1998.

QUINN, J., MAW, J., RAMOTOR, K., et al. Octylcyanoacrylate tissue adhesive versus suture wound repair in a contaminated wound model. Surgery, v.122, n.1, p.69-72, 1997.

QURESHI, A., DREW, P.J., DUTHIE, G.S., et al. N-Butyl cyanoacrylate adhesive for skin closure of abdominal wounds: preliminary results. Annual Review College Surgery England, v.79, n.6, p.414-415, 1997.

ROBBINS, S.L., COTRAN, R.S., KUMAR, V. Inflamação e reparo. In: ROBBINS, S.L., COTRAN, R.S., KUMAR, V Patologia estrutural e funcional. Rio de Janeiro : Guanabara Koogan, 1991. p.33-72.

TSENG, Y.C., TABATA, Y., HYON, S.H., et al. In vitro toxicity test of 2-cyanoacrilato polymers by cell culture method. Journal of Biomedical Materials Research, v.24, n.10, p.1355-1367, 1990.

Ciência Rural, v. 31, n. 2, 2001. 